\title{
How Gentrified Community Influences Residents' Mental Health - Evidence from London?
}

\author{
Rong LIU
}

\author{
Guangzhou Foreign Language School \\ *Corresponding author. Email: 1351670579@qq.com
}

\begin{abstract}
Knowing that green space has an impact on residents' mental health, it also induces green gentrification which is likely to further arise mental health problems. The article targets two main objectives: 1. Identify whether gentrification happens in areas with improved green amenities. 2. Evaluate the impact of green gentrification on mental health and why are there such impacts. The results show the harmful effects of gentrification on households' mental health.
\end{abstract}

Keywords: Gentrification, Mental Health, Green Gentrification

\section{INTRODUCTION}

In the era when developing countries are suddenly rising to prominence, gentrification takes a significant part in the transition as the middle class has quickly emerged. Therefore, the article intends to elaborate on this crucial role in urban studies, seeking its meaning in urban redevelopment. In the meanwhile, increasing awareness of protecting the environment has arisen among the society. The government is paying more attention to urban planning, containing the green factor tool which has been conducted in cities all over the world to improve sustainability. Even some authorities consider the proportion of the green area a performance target [1]. So this progress attracts people with higher socioeconomic positions who are affordable for the higher property value to enter the neighborhood, in order to enjoy the improved green amenities such as parks and wetlands. This phenomenon also seems to be a type of gentrification, which is normally known as green gentrification. What's more, green gentrification is not only affecting people's financial situation by putting higher pressure on them, the influence on the health side is also worthy to discuss. In terms of the physical aspect, the influences are obvious, however, the mental aspect is always ignored. So this article first tries to verify the impact of green space on gentrification and illustrates its effects on households' mental health.

\section{LITERATURE REVIEW}

\subsection{Defining gentrification}

Gentrification came from the word "gentry" which means people with a high socioeconomic position ranking only second to the nobility. And the concept of gentrification was firstly raised by Ruth Glass in the 1960s to portray the phenomenon happening in the East End of London [2]. This phenomenon refers to the increase in neighborhood affluence [3] indicating the changes in income distribution, percentage of race, percentage of residents receiving high education, percentage of the population being employed in a professional occupation, percentage of young adults, and increasing housing price [4]. There are the following possible causes of gentrification. The first is the policy. In order to mitigate the effects of housing decadence in the inner-city area [5], the government redeveloped the neighborhood and consequently attracted the middle class who are typically white, professional, well-educated, and young(Marcuse 1985, 198-99). Also, the government provides tax incentives, and bank lowers the mortgage rate to attract the residents. The cheap housing and proximity to the workplace also contribute to people's strong willingness to enter the neighborhood, especially for the employees intending to reduce the commuting time. Additionally, Culture is a significant factor as well, the anti-suburban 
attitudes, architecture styles, and age-long history all contribute to increasing demand from wealthy groups to enter the city center(Holland01/01/2016). What's more, there are other kinds of gentrification like retailing gentrification which is induced by the change in retailing environment, green gentrification due to the construction of green space, climate gentrification referring to the building of climate-resistant infrastructure, transit-induced gentrification which is also led by the government and tourism gentrification which is induced by the rapid economic growth in tourism venues [6].

\subsection{Impact of gentrification}

Negative effects: the upgrading of cities seems to be imperative to ensure sustainability, however, it causes unexpected consequences influencing different groups. Displacement is the most frequent word in urban gentrification topic, which indicates the change in the neighborhood population composition from underprivileged group to more affluent group as the surge in rents and housing prices add higher financial pressure on long-term residents and consequently induce eviction [7]. Displacement is a heated topic in human geography (Brickell et al., 2017), and the indicators of it are always controversial. Atkinson [8] concluded an indicator of displacement: the property transforms from being rented to the owned one(DeGiovanni, 1984), the accommodation quality after moving away from gentrifying area degrades(Hartman, 1979a). And those indicators make a progress from being a rough one to a more improved and precise one. Except for involuntary displacement, indirect displacement exists. Psychological displacement means that reminders in gentrifying areas may think they are not culturally and socially involved in the community. As their original neighbor leaves and causes disrupted social networks [9]. And the surrounding facilities and services change to cater to the new entrants, so there is an increase in living costs, or those facilities can not satisfy remainders' preference. The impact of gentrification is also highly relevant to spatial injustice [10]. In the case of transitoriented development, combining the development in public transit and land value together. The gentrification problem is arisen due to the higher property value, which means that the MTR is unavailable to the underprivileged group who may demand public transit the most [11], resulting in spatial injustices. Ethnic segregation and discrimination are acting as ill effects of gentrification too. The increasing capital investment in the city center is associated with the amplifying class segregation [12].

Positive effects: gentrification seems to have negative effects in many aspects, but this does not automatically mean that it has no benefits. Firstly, the modification in crime rate within the neighborhood is evident, Papachristos used the increase in the number of coffee shops as an indicator of gentrification and claimed this linked to the lower possibility of homicide and robbery, especially in white neighborhoods [13]. Secondly, the middle class is considered a crucial component of the economy, gentrification seems to introduce economic prosperity into inner-city areas [14]. The economic opportunities incentivize the landowners to switch their land use from manufacturing factories to more commercial and residential use. More positions in the tertiary sector like restaurants are created due to the rising demand from the new wealthier group. Therefore, industrial reconstructing happens [15]. In addition, gentrification also shows a favorable impact on the households' perceptions of neighborhood collective efficacy because the middle class transfers the value for demanding high-quality resources and community initiatives [16]. Although the benefits seem to exist, the costs of gentrification may outweigh the benefits from improving the physical environment, preventing urban sprawl, and increasing tax revenue. Furthermore, those positive effects largely depend on nonresearch literature instead of a systematic review. So it takes time to see the real consequences [17].

\subsection{Green gentrification}

The city requires more green amenities for maintaining its sustainability. The developers construct more green infrastructure. For example, parks, gardens, greenbelts, playgrounds, and open spaces. However, the improved amenities for residents accompany the rapid process of gentrification, known as green gentrification. The influx of wealthier groups leads to further redevelopment and upgrading to satisfy their needs, adding on property taxes, which results in a higher possibility of evictions as housing becomes less affordable to the low-income group [18].

Green gentrification leads to further negative effects, involving hits on mental health. For the low-income group who temporarily lives in the areas facing gentrification by renting, the anxiety and pressure due to the fear of being displaced [19]. However, it indeed brings positive effects on other groups, for example, the new entrants and longterm residents. The study illustrates the decrease in distance to useable green space contributes to better mental health such as decreased anxiety [20]. What's more, gentrification brings about social upgrading, which is rarely happened before because the original gentrifying area is considered as an ignored, poor place, so it is likely to generate surprising effects on people's mental health [21]. For example, more options are provided as businesses follow the affluent groups to make a profit. And the government may strengthen the security in the community 
[22]. Oppositely, some remainders can not accept huge changes [23] and feel isolated or think of themselves as being culturally displaced, consequently at risk of depression(Tran et al., 2020).

The data shows a strong positive correlation between housing prices and green space due to residents' high willingness to access large private gardens. The house price value saw an increase of $0.077-0.083 \%$ within $1 \mathrm{~km}$ of park areas. For regional/Metropolitan parks within $600 \mathrm{~m}$, the house price value also witnessed an increase of $1.8-2.9 \%$. Although including variables like housing type and size, housing age, and deprivation may weaken the correlation, it still seems apparently correlated. In addition, the characteristics of green space also play an important role, an open space with better aspects, larger area, and better reputation is likely to more significantly influence the housing value. Increment of the housing price around less functional or appealing open spaces tends to be lesser [24]. $\mathrm{Kim} \& \mathrm{Wu}$ [25] claimed that the passive, natural, and medium-sized green spaces accelerate gentrification in the short term, indicated by the higher property value, education level. After considering the characteristics, the proximity to the green space factors in the increasing housing price.

\section{METHODOLOGY}

\subsection{Flow chart}

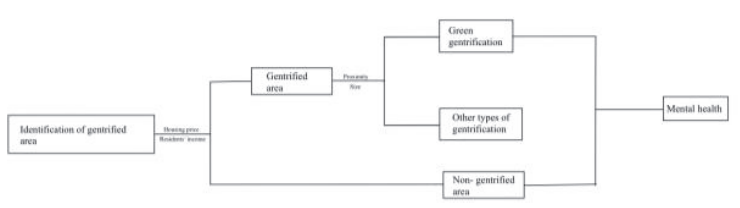

Figure 1 Identification of gentrified area

\subsection{Gentrification}

Gentrification refers to the increase in neighborhood affluence indicating by the changes in income distribution, percentage of race, percentage of residents receiving high education, percentage of the population being employed in a professional occupation, percentage of young adults. So there are various actions to identify whether the community is being gentrified. Housing price and residents' income level are two indicators commonly used in research(Tran et al., 2020). As the housing price and income level increase naturally due to other factors, only the neighborhood that has a growth rate that is higher than the average increase rate should be considered as the gentrified neighborhood. Similarly, the region whose rate of increase above the average increase of households' income level should be classified as the gentrified area.

\subsection{Green gentrification}

This research tends to explore green gentrification--the construction of green infrastructure contributes to the acceleration of gentrification progress. Therefore, the following factors are demonstrating how the characteristics of green space affect the gentrification process. The impact of green space depends on the proximity to the green space. From the past studies, Cole et al concluded that the size of the buffer of $400 \mathrm{~m}$ is an acceptable walking distance. The further the green space is from the community, the less impact it can cause. Green space can be roughly categorized as parks, gardens, greenbelts, playgrounds, and open space, and the difference in green space determines its valuation. The property value is largely influenced by the size of green space. Thus, it is significant to involve the consideration of the size when measuring their effects [26]. $\mathrm{Kim} \& \mathrm{Wu}$ found that the passive, natural and mediumsized green space promotes the gentrification process. And it is indicated by the increase in housing price and the residents' education level, whereas the low-income group and the ethnic minority group leaves.

\subsection{Impact on mental health}

Green gentrification leads to negative effects, involving the hits on mental health due to financial pressure or psychological displacement. So the relationship between the access to green space, types of green space, and mental health of residents will be discussed below.

\subsection{Statistical analyses}

The regression analysis is being adopted. This model contains an independent variable and one dependent variable. And the sample data is required to build a linear or non-linear mathematical model which can quantitatively analyze the relationship between the dependent variable and the independent variable. In the case of green gentrification, we consider the dependent variable as the housing price(Y1), which is the indicator of gentrification. And other independent variables are accessibility to green space(X1) and green space surface(X2). Assuming that the relationship between the independent variable and the dependent variable is linear, $\mathrm{Y} 1$ is influenced by $\mathrm{Xi}$, a regression model is built. In order to show the impact of gentrification on mental health, regression models are also used to build relationships between the extent of gentrification and some mental health indexes including anxiety levels and panic disorder rates. 


\section{RESULTS}

\subsection{Green space surface and higher house price}

Figure1 shows a positive trend, indicating that a larger green space surface contributes to the increasing medium house price in various boroughs of London. As the rapid process of urbanization exploits the limited land in the urban area. There is a climbing demand from people for a more mixed neighborhood, resulting in a shortage of land in cities. In the meanwhile, higher requirements for green spaces raises due to their social and ecological function [27], for example, mitigating environmental issues such as the heat island effects [28] and strengthening people's health. Therefore, green spaces are considered a luxury in city areas, which factor in the change of property values. Housing price surges not only because of people's strong willingness towards green space but also speculation, showing that a higher income profile appears in the community. We can also see this strong correlation from figure2, which proves that larger green space brings in the more affluent group.

In addition, movements of demographic structure indicate a likely change in investment preferences. Tertiary industries tend to invest in the area, trying to satisfy middle's class demand. Or more businesses are set up around the residential location to get close proximity to their consumers and their existing or potential employees. What's more, visible economical prospects that are indicated by the entrance of middle classes attract investors to redevelop the region over and over, which results in another round of gentrification again as high-income groups are willing to take advantage of higher accessibility to amenities that are constructed during the redevelopment period. So it seems like a cycle, which continuously triggers gentrification effects.

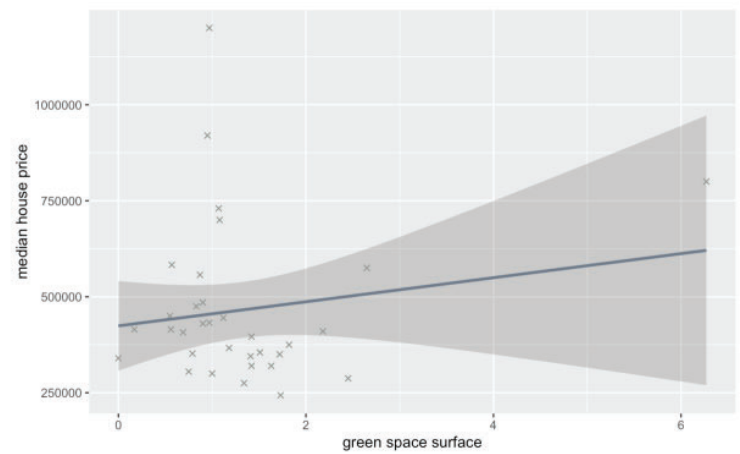

Figure 2 The relationship between green space surface and median house price

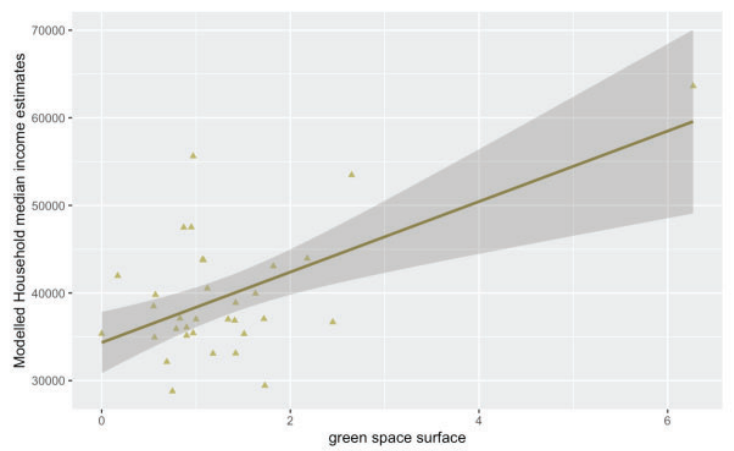

Figure 3 The relationship between green space surface and median household income estimates

\subsection{Green space and mental health}

From figure 3, we can notice that there is a negative relationship between the level of anxiety and households' accessibility to the green space in 34 boroughs of London. Considering anxiety as an indicator of people's mental health, the downward trend demonstrates the influence of green space on mental health. There is also evidence from various studies showing that other mental health indexes are linked to the accessibility to green space, not only anxieties [29]. What's more, many cities now consider green space as a kind of health care facility. As it promotes physical health and social attachment when residents interact with each other in a shared space [30].

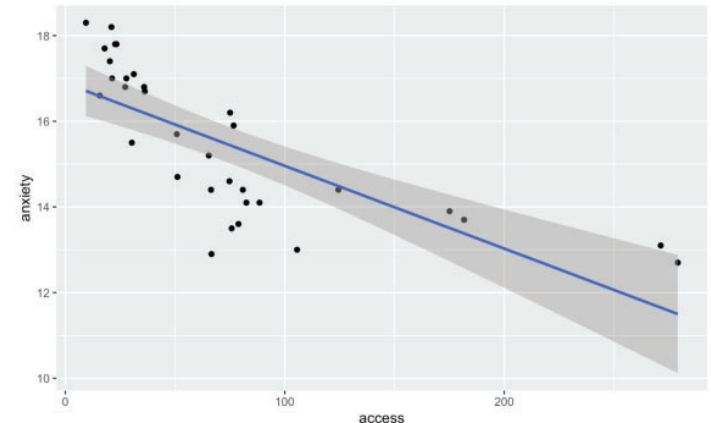

Figure 4 The relationship between accessibility to green space and anxiety

\subsection{Gentrification and mental health}

According to figure 4, a clear upward trend is presented, representing that panic disorder rates per 1000 population rises while median house price increases in London. So the gentrification process which accompanies higher property value induces some psychological problems, including panic disorder rate. For renters who prefer to remain in gentrifying areas, they are facing climbing daily expenses that both involve rents and other costs. Stress-related health 
problems easily arise due to financial pressure and the fear that they are being evicted. Nevertheless, for those house owners who have a relatively stable financial situation, their psychological problems may be different. The disrupted social network after their neighbors is leaving and the declining satisfaction because of the change in investment preferences of developers both contribute to a worse mental state.

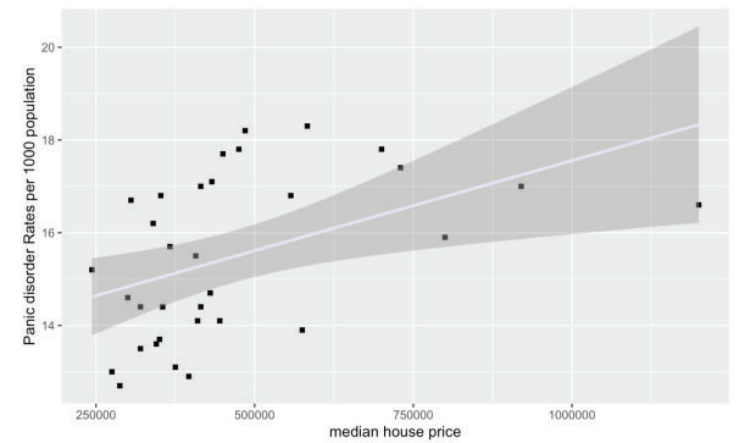

Figure 5 The relationship between median house price and panic disorder rates per 1000 population

From the increasing median house price and median income estimates, we can clearly see the existence of green-induced gentrification. Moreover, both green space and gentrification contribute to changes in the state of mental health. In terms of green space, its influences on health are mostly positive. By contrast, gentrification indicates an adverse effect on residents' mental health, including households that are being evicted or remaining in the gentrified area.

\section{CONCLUSION}

There are few studies in the relationship between gentrification and mental health before, ignoring the fact that the improvement in the neighborhood does harmfully affect the citizen. Also, green space is generally considered a promoter of residents' health index in many studies. However, it indirectly threatens households' psychological situation through accelerating gentrification. Therefore, this article partly focuses on the consequences on mental health, which demonstrates how gentrification worsens residents' mental circumstances. In general, previous studies mainly research a country as a whole, which is too large in scale and less specific and accurate. Nevertheless, this article scales down the subject, dividing London into 33 boroughs to discuss and compare their differences to conclude the relationships between various variables.

House price, household income, and mental health all seem to be comprehensive concepts, which could be influenced by plenty of factors. For example, economic growth is considered a factor that results in a greater housing price and a climbing average income level. What's more, stress-related illness happens commonly in middle to high-tier groups due to their working environment. All those variables that may affect the results should be taken into account in future studies.

\section{REFERENCES}

[1] Juhola, S. (2018). Planning for a green city: The Green Factor tool. Urban Forestry \& Urban Greening, 34, 254-258. https://doi.org/10.1016/j.ufug.2018.07.019

[2] -, K. S. (2020, March 24). How Gentrification Affects Mental Health. MindPath Care Centers. https://www.mindpathcare.com/blog/howgentrification-affects-mental-health/.

[3] Cole, H. V., Garcia Lamarca, M., Connolly, J. J., \& Anguelovski, I. (2017). Are green cities healthy and equitable? Unpacking the relationship between health, green space and gentrification. Journal of Epidemiology and Community Health. https://doi.org/10.1136/jech-2017-209201

[4] Cole, H. V. S., Triguero-Mas, M., Connolly, J. J. T., \& Anguelovski, I. (2019). Determining the health benefits of green space: Does gentrification matter? Health \& Place, 57, 1-11. https://doi.org/10.1016/j.healthplace.2019.02.001

[5] Hackworth, J., \& Smith, N. (2001). The changing state of gentrification. Tijdschrift Voor Economische En Sociale Geografie, 92(4), 464-477. https://doi.org/10.1111/1467-9663.00172

[6] Cole, H. V., Mehdipanah, R., Gullón, P., \& TrigueroMas, M. (2021). Breaking down and building up: Gentrification, its drivers, and urban health inequality. Current Environmental Health Reports, 8(2), 157-166. https://doi.org/10.1007/s40572-021-00309-5

[7] Newman, K., \& Wyly, E. K. (2006). The Right to Stay Put, Revisited: Gentrification and Resistance to Displacement in New York City. Urban Studies, 43(1), 23-57. https://doi.org/10.1080/00420980500388710

[8] Atkinson, R. (2000). Journal of Housing and the Built Environment, 15(4), 307-326. https://doi.org/10.1023/a:1010128901782

[9] Mullenbach, L. E., \& Baker, B. L. (2018). Environmental Justice, Gentrification, and Leisure: A Systematic Review and Opportunities for the Future. Leisure Sciences, 42(5-6), 430-447. https://doi.org/10.1080/01490400.2018.1458261 
[10] Elliott-Cooper, A., Hubbard, P., \& Lees, L. (2019). Moving beyond Marcuse: Gentrification, displacement and the violence of un-homing. Progress in Human Geography, 44(3), 492-509. https://doi.org/10.1177/0309132519830511

[11] He, S. Y., Tao, S., Hou, Y., \& Jiang, W. (2018). Mass transit railway, transit-oriented development and Spatial Justice: The competition for prime residential locations in Hong Kong since the 1980s. Town Planning Review, 89(5), 467-493. https://doi.org/10.3828/tpr.2018.31

[12] Wyly, E. K., \& Hammel, D. J. (2004). Gentrification, segregation, and discrimination in the American urban system. Environment and Planning A: Economy and Space, 36(7), 1215-1241. https://doi.org/10.1068/a3610

[13] Papachristos, A. V., Smith, C. M., Scherer, M. L., \& Fugiero, M. A. (2011). More coffee, less crime? the relationship between gentrification and neighborhood crime rates in Chicago, 1991 to 2005. City \& Community, 10(3), 215-240. https://doi.org/10.1111/j.1540-6040.2011.01371.x

[14] Atkinson, R. (2004). The evidence on the impact of gentrification: New lessons for the urban renaissance? European Journal of Housing Policy, 4(1), 107-131. https://doi.org/10.1080/1461671042000215479

[15] Lester, T. W., \& Hartley, D. A. (2014). The long-term Employment impacts of gentrification in the 1990s. Regional Science and Urban Economics, 45, 80-89. https://doi.org/10.1016/j.regsciurbeco.2014.01.003

[16] Steinmetz-Wood, M., Wasfi, R., Parker, G., Bornstein, L., Caron, J., \& Kestens, Y. (2017). Is gentrification all bad? the positive association between gentrification and individuals' perceived neighborhood collective efficacy in Montreal, Canada. International Journal of Health Geographics, 16(1). https://doi.org/10.1186/s12942-017-0096-6

[17] Atkinson, R. (n.d.). 2021. Does gentrification help or harm urban neighborhoods? An assessment of the evidence base in the context of the new urban agenda. Centre for Neighbourhood Research, Paper. Retrieved September 18, 2021, from https://www.academia.edu/316541/Does_Gentrificati on_Help_or_Harm_Urban_Neighbourhoods_An_Ass essment_of_the_Evidence_Base_In_the_Context_of _the_New_Urban_Agenda.

[18] Hall, R., \& Ogden, P. E. (1992). The Social Structure of New Migrants to London Docklands: Recent
Evidence from Wapping. The London Journal, 17(2), 153-169. https://doi.org/10.1179/1dn.1992.17.2.153

[19] Fullilove, M. T., \& Wallace, R. (2011). Serial Forced Displacement in American Cities, 1916-2010. Journal of Urban Health, 88(3), 381-389. https://doi.org/10.1007/s11524-011-9585-2

[20] Nutsford, D., Pearson, A. L., \& Kingham, S. (2013). An ecological study investigating the association between access to urban green space and mental health. Public Health, 127(11), 1005-1011. https://doi.org/10.1016/j.puhe.2013.08.016

[21] Wilder, V., Mirto, A.-L., Makoba, E., \& Arniella, G. (2017). The health impact of gentrification. Journal of General and Emergency Medicine.

[22] Shmool, J. L., Yonas, M. A., Newman, O. D., Kubzansky, L. D., Joseph, E., Parks, A., Callaway, C., Chubb, L. G., Shepard, P., \& Clougherty, J. E. (2015). Identifying Perceived Neighborhood Stressors Across Diverse Communities in New York City. American Journal of Community Psychology, 56(1-2), 145-155. https://doi.org/10.1007/s10464-015-9736-9

[23] Galster, G. C. (2008). Quantifying the Effect of Neighbourhood on Individuals: Challenges, Alternative Approaches, and Promising Directions. Schmollers Jahrbuch, 128(1), 7-48. https://doi.org/10.3790/schm.128.1.7

[24] Smith, D. (2010, September). Valuing housing and green spaces: Understanding local amenities, the built environment and house prices in London. www.london.gov.uk. Retrieved September 18, 2021.

[25] Kim, S. K., \& Wu, L. (2021). Do the characteristics of new green space contribute to gentrification? Urban Studies, https://doi.org/10.1177/0042098021989951

[26] Panduro, T. E., \& Veie, K. L. (2013). Classification and valuation of urban green spaces - a hedonic house price valuation. Landscape and Urban Planning, 120, 119-128. https://doi.org/10.1016/j.landurbplan.2013.08.009

[27] Barbosa, O., Tratalos, J. A., Armsworth, P. R., Davies, R. G., Fuller, R. A., Johnson, P., \& Gaston, K. J. (2007). Who benefits from access to green space? A case study from Sheffield, UK. Landscape and Urban Planning, 83(2-3), 187-195. https://doi.org/10.1016/j.landurbplan.2007.04.00 4 
[28] Sun, R., \& Chen, L. (2017). Effects of green space dynamics on urban heat islands: Mitigation and diversification. Ecosystem Services, 23, 38-46. https://doi.org/10.1016/j.ecoser.2016.11.011

[29] Nutsford, D., Pearson, A. L., \& Kingham, S. (2013). An ecological study investigating the association between access to Urban Green Space and mental health. Public Health, 127(11), 1005-1011. https://doi.org/10.1016/j.puhe.2013.08.016

[30] Barton, J., \& Rogerson, M. (2017). The importance of greenspace for Mental Health. BJPsych. International, 14(4), 79-81.

https://doi.org/10.1192/s2056474000002051 